\title{
Lifestyle in Female Teachers: Educational Intervention Based on Self-Efficacy Theory in the South of Fars Province, Iran
}

\author{
Fariba Abbasi $\left(\mathbb{D}\right.$, Leila Ghahremani $\left(\mathbb{D}\right.$, Mahin Nazari $\left(\mathbb{D}\right.$, Mohammad Fararouei $\mathbb{D}^{\text {, }}$, \\ and Zakieh Khoramaki
}

Research Center for Health Sciences, Institute of Health, Department of Health Promotion, School of Health, Shiraz University of Medical Sciences, Shiraz, Iran

Correspondence should be addressed to Leila Ghahremani; ghahramanl@sums.ac.ir

Received 24 April 2021; Revised 27 October 2021; Accepted 18 November 2021; Published 6 December 2021

Academic Editor: Matteo Curcuruto

Copyright ( 2021 Fariba Abbasi et al. This is an open access article distributed under the Creative Commons Attribution License, which permits unrestricted use, distribution, and reproduction in any medium, provided the original work is properly cited.

\begin{abstract}
Introduction. Today, improving lifestyles and promoting health are basic needs for human society. The main goal in promoting health is to achieve healthy lifestyle behaviors, and self-efficacy is one of the factors influencing people's lifestyle. Therefore, the impact of educational intervention based on self-efficacy theory on improving lifestyles of the female teachers in Galledar was investigated. Method. This study was a semiexperimental study with educational intervention with a control group that was performed on 120 teachers in Galledar. Data collection tools included demographic information questionnaires, healthpromoting lifestyle questionnaires, and Sherry's self-efficacy questionnaire. Data were analyzed using SPSS 25 software. Result. The mean age and standard deviation of teachers in the control and intervention groups were $33.40 \pm 5.68$ and $32.83 \pm 6.46$ years, respectively. Health-promoting lifestyle variables are significant correlation with self-efficacy and overall lifestyle index. Six dimensions which consisted of spiritual growth and self-actualization, health responsibility, interpersonal relationships, stress management, exercise and physical activity, and nutrition showed significant statistical differences before and after educational intervention $(P=0.001)$. Conclusion. Due to the sensitive role of teachers as an effective human force in the development and evolution of society and their students' role modeling, the authorities should formulate policies, regulate educational interventions, and design strategies for promoting self-efficacy beliefs and promoting a healthy lifestyle for all teachers. We suggest that other methods and theories of behavior change be used in future studies to promote a healthy lifestyle.
\end{abstract}

\section{Introduction}

Health is one of the most important and basic human needs and a tool to achieve the goals and successes of individuals and communities that must be planned throughout life to maintain health [1]. One of the determinants of people's health is their lifestyle [2].

Lifestyle is a relatively coherent set of all a person's behaviors and activities during life [3]. A health-promoting lifestyle helps maintain and strengthen a person's level of health and self-actualization. It also leads to optimal wellbeing, individual development, and creative life, and it has six dimensions of interpersonal relationships, health respon- sibility, spiritual growth and self-actualization, stress management, nutrition, and physical activity [4].

More than a third of deaths worldwide are due to poor personal and social lifestyles. The World Health Organization said, in a statement at the first World Conference on Healthy Lifestyle in 2011 in Moscow, that $60 \%$ of global deaths and $80 \%$ of deaths in developing countries are currently due to unhealthy lifestyles. The share of this factor in global mortality will reach to $75 \%$ by 2030 [5], and one of the main reasons for the increase in noncommunicable diseases is the adoption of unhealthy behaviors, too [6].

Adopting healthy behaviors has a significant impact on reducing health costs, mortality, and life stressors, as well 
as increasing life expectancy and improving the quality of life of individuals, which have a special importance and place in society $[7,8]$. About $80 \%$ of women aged $18-55$ have high-risk, lifestyle-related behaviors that are preventable [9]. However, the results of a study by Tamakoshi et al. showed that $18.5 \%$ of deaths among women can be prevented if lifestyle management is managed [10].

Evidence suggests that self-efficacy is related to lifestyle $[11,12]$. It is one of the factors influencing the lifestyles of individuals and shows people's confidence and confidence in their skills and ability to successfully perform behavior in certain situations [13-15]. Studies have shown that selfefficacy is associated with a variety of health-promoting lifestyle behaviors, such as smoking cessation, diet, and physical activity [16, 17]. It also leads to better self-management, increased life expectancy, and adjusted health behaviors [18], and it is one of the factors that lead to the promotion of women's general health [19]. There are four major sources of self-efficacy: performance gains (such as previous successful experiences), succession experiences (such as using a successful model), verbal encouragement (encouragement from influential people such as friends and family), and emotional arousal. [15, 20-22]. According to the results of a study by Zeldin et al. on women's self-efficacy beliefs in math, science, and technology, self-efficacy leads to the endurance and flexibility needed to overcome scientific and professional barriers [23].

One of the ways to achieve the goal of following up on diseases is to use appropriate educators for the target community. Meanwhile, the role of teachers as facilitators of general education and the basic role models of students [24] are very important [22].

A female teacher is responsible for a dual role, one in the family and the other in the work [25]. During their daily work, school teachers face a variety of stressors (for example, noise in the classroom, problems with students and their parents, and extra administrative work) that lead to significant chronic stress [22]. However, teachers are the main pillar of education, and female teachers are also responsible for raising children at home and play an important role in educating the next generation of the country $[9,22]$. They need to have the necessary skills and abilities to play their role in the best possible way, because the main burden of educating students is on teachers [25]. By adhering to healthy behaviors and adopting a healthy lifestyle, they can be an effective role model for their families and students [26].

The results of a study by Charkazi et al. showed that $84 \%$ of teachers working in Gorgan schools had a semifavorable lifestyle [27]. In their study, Pirzadeh et al. found that $14.5 \%$ of teachers had a semidesirable and desirable lifestyle, of which $26.1 \%$ was related to nutrition, $76 \%$ to physical activity, and $29.2 \%$ to smoking or exposure. And $21.9 \%$ had a semioptimal lifestyle to deal with stress [26].

Health-promoting lifestyle training is one of the most important factors in increasing knowledge and self-efficacy [28] and improving women's performance to improve health [29]. The effectiveness of health education programs largely depends on the correct use of the theories and models used in it, and intervention programs based on a theoretical framework can increase the individual's understanding of the factors affecting behavior change such as psychological and social causes and biology, to facilitate the process of changing health behaviors [30].

Therefore, considering the importance of lifestyle variables in promoting health and increasing quality of life, the sensitive role of teachers as an influential human force in the development and evolution of society and students' role models $[24,27]$ as well as the uncertainty of the role of selfefficacy in health-promoting lifestyle [31], and finally the lack of interventional studies on teachers' lifestyle, this study was conducted to investigate the effect of educational intervention based on self-efficacy theory on improving the lifestyle of female teachers in Galledar in the south of Fars province.

\section{Materials and Methods}

This study was a semiexperimental intervention research conducted in 2018-19 with the aim of investigating the effect of educational intervention based on self-efficacy theory on improving lifestyles of all female teachers in Galledar located in Fars province.

The sample size of this study was estimated based on similar previous studies [32], and considering the formula for the average difference between the two groups, as well as the first type of error of $5 \%$ and the test power of $80 \%$, we estimated 48 people for each group. The drop ranged from $20 \%$ to $60 \%$ in each group.

The statistical population of this study included all female teachers working in Galledar in 2018-19. There were a total of six girl schools, four elementary schools, and two junior high schools in the city. With the two-step sampling method, we first divided the schools into primary and junior high schools, and then, we randomly assigned two primary schools and one junior high school to the test group, as well as two primary schools and one junior high school to the control group. Then, from the list of teachers of the mentioned schools, we selected the desired samples using simple random sampling.

Inclusion criteria for participating in the study were being a female, being a teacher, residing in the city of Galledar, having a continuous and consecutive attendance at the training, willing to participate in the study, and completing the conscious consent form. Individuals were excluded from the study if they changed their place of residence outside of the research environment, had more than one absence session in the training classes, or did not attend one of the pretest or posttest stages.

\subsection{Research Tools}

(a) The demographic variable questionnaire included age, marital status, level of education, number of deliveries, tobacco use, spouse's education rate, spouse's job, and average household income

(b) The health-promoting lifestyle questionnaire (Walker et al. 1987) measures a health-promoting lifestyle by focusing on initiatives and individual perception of 
self-improvement, self-fulfillment, and individual satisfaction. It consists of 54 items with six dimensions of nutrition with 11 questions, physical activity with 13 questions, responsibility in health with 8 questions, stress management with 6 questions, interpersonal relationships with 8 questions, and spiritual growth and self-actualization with 8 questions. Each item in this questionnaire is given a score of one (never) to four (always). The overall score of health-promoting behaviors is in the range of 52 to 208, and a separate score is calculable for each dimension. Mohamadi conducted a study in Iran. He reported the Cronbach alpha coefficient for the entire tool at 0.82 and for the subbranches in the range of 0.64 to 0.91 [33]

(c) Sherry general self-efficacy questionnaire (1982) includes 17 items and is graded on a 1-5 Likert scale to measure self-efficacy in doing things. In this scale, scores of 1 to 5 from right to left belong to questions $15,13,9,8,3$, and 1 , and the rest of the questions are scored in reverse, i.e., from left to right. Thus, the highest efficacy score on this scale is 85 and the lowest is 17. Barati has translated and presented the Persian version of this questionnaire [34]

In order to conduct the research, we firstly obtained a license from the research deputy of Shiraz University of Medical Sciences, and then, we made the necessary coordination with the Department of Education of the Galledar region. In the next step, the teachers included in the present study were justified on how we plan and keep the information confidential. Then, we collected the information and distributed the questionnaires before the educational intervention in both groups.

We developed educational content based on authoritative sources in six dimensions of healthy lifestyle using selfefficacy theory structures, which are described in Table 1. We taught six 40- to 45-minute training sessions through interactive lecturing, group discussion, and the use of media such as educational pamphlets and slide shows as part of the PowerPoint program.

In order to enhance the self-efficacy of the participants, they were asked to share their successful experiences with others. To this end, one of the teachers who had implemented effective methods of stress management was invited to present his experiences and answer questions (mastery experiences and role models) so that the learners who had participated in the discussion for verbal persuasion were encouraged. Individual counseling was also conducted to reinforce participants who were not very successful in implementing health-promoting behaviors, and they were asked to break down their goals into smaller, more achievable steps and were successfully encouraged after each step. Sending persuasive text messages also encouraged the participants. Participants were also allowed to express feedback on their thoughts, feelings, and experiences in performing physical activity, adhering to a healthy diet, and performing stress management techniques. Individual counseling was also provided by a psychologist to participants who had difficulty controlling their emotions, moods, and physiology.

It should be noted that throughout the intervention, the teachers of the control group were unaware of the implementation of the relevant educational program.

Two months after the implementation of the educational intervention, we performed posttests on both the test and control groups of teachers using the same initial questionnaires.

We analyzed the collected data using SPSS statistical software version 25. In addition to descriptive analysis, we used the chi-square test and independent $t$-test to compare the variables of the two groups and paired $t$-test for the intragroup comparison.

\section{Results}

A total of 120 teachers participated in the study. The mean age and standard deviation of teachers in the control and intervention groups were $33.40 \pm 5.68$ and $32.83 \pm 6.46$ years, respectively; there was no significant difference in age between these two groups $(P$ value $=0.61)$. In Table 2 , we presented information on participants in the two groups of intervention and control in terms of age, average number of deliveries, and average service history by year and average daily physical activity of teachers. The intervention and control groups were homogeneous in terms of the three variables mentioned and were not significantly different (Table 3).

We have provided the correlation coefficient of the research variables in Table 4 . The results show that all health-promoting lifestyle variables are related to each other and to the overall lifestyle index, and they also have a significant correlation with self-efficacy.

\section{Discussion and Conclusion}

The aim of this study was to investigate the effect of education based on self-efficacy theory on improving the lifestyle of female teachers. The results of this study show that the overall score of the health-promoting lifestyle in the intervention group increased significantly after two months of the training program. Therefore, the overall score of lifestyles in the intervention group increased from $137.53 \pm$ 9.41 to $155.68 \pm 24.58$; this indicates the positive effect of the training program.

Six dimensions of spiritual growth and self-actualization, health responsibility, interpersonal relationships, stress management, exercise and physical activity, and nutrition showed significant statistical differences before and after educational intervention. These observations suggest that improving health-promoting lifestyle components is associated with self-efficacy. A study conducted by Mirghafourvand also showed that there was a positive and significant correlation between self-efficacy and health-promoting lifestyle and its subdomains [35]. The study done by Amiri et al. showed a significant relationship between health and well-being and self-efficacy and health-enhancing lifestyle [36]; it is consistent with the present study. The results of 
TABLE 1: Summary of training sessions based on self-efficacy theory to improve health-promoting lifestyles.

\begin{tabular}{|c|c|c|}
\hline $\begin{array}{l}\text { First } \\
\text { session }\end{array}$ & Health responsibility & $\begin{array}{c}\text { Lectures to create an inner interest in increasing self-efficacy in a health-promoting lifestyle } \\
\text { and that all people are responsible for their own health, along with providing educational } \\
\text { pamphlets. }\end{array}$ \\
\hline $\begin{array}{l}\text { Second } \\
\text { session }\end{array}$ & $\begin{array}{l}\text { Stress management, } \\
\text { self-actualization }\end{array}$ & $\begin{array}{c}\text { "Reminding of direct experiences (skill experience)" as the main factor of self-efficacy and } \\
\text { training stress management and self-fulfillment strategies. }\end{array}$ \\
\hline $\begin{array}{l}\text { Third } \\
\text { session }\end{array}$ & Jutrition and physical activity & $\begin{array}{l}\text { Using the "succession experiences" factor to help participants recall successful experiences. } \\
\text { We asked successful people in the class (teachers) who have had successful experiences in } \\
\text { promoting health behaviors (such as having a successful diet or exercising regularly) to share } \\
\text { their experiences with others. }\end{array}$ \\
\hline $\begin{array}{l}\text { Fourth } \\
\text { session }\end{array}$ & $\begin{array}{l}\text { Stress management and } \\
\text { self-actualization }\end{array}$ & $\begin{array}{l}\text { Verbal and nonverbal persuasion through the practice of previous sessions to control stress } \\
\text { and self-actualization strategies. Encouraging participants to build interpersonal } \\
\text { relationships in the same session and giving positive feedback to the participants' discussions } \\
\text { with each other. }\end{array}$ \\
\hline $\begin{array}{l}\text { Fifth } \\
\text { session }\end{array}$ & $\begin{array}{l}\text { Interpersonal relationships, } \\
\text { health responsibility }\end{array}$ & $\begin{array}{l}\text { Using interactive speech to create a positive mood by encouraging friendly relationships in } \\
\text { participants to implement successfully a health-promoting lifestyle plan. We asked them to } \\
\text { adjust their decisions to smaller, more accessible steps and hold themselves accountable for } \\
\text { their decisions. We encouraged them with the successful completion of part of the program. }\end{array}$ \\
\hline $\begin{array}{l}\text { Sixth } \\
\text { session }\end{array}$ & $\begin{array}{l}\text { Physical activity, nutrition, } \\
\text { stress management }\end{array}$ & $\begin{array}{l}\text { We allowed individuals to express their thoughts and feelings when engaging in physical } \\
\text { activity, following a healthy diet, and performing stress management practices, thus } \\
\text { providing them with feedback on their condition. }\end{array}$ \\
\hline
\end{tabular}

TABLE 2: Demographic characteristics of the teachers under study.

\begin{tabular}{|c|c|c|c|c|c|}
\hline Variable & Group & Domain & Mean & Standard deviation & ${ }^{*} P$ value \\
\hline \multirow{2}{*}{ Age } & Experiment & $23-48$ & 33.40 & 5.68 & \multirow{2}{*}{0.61} \\
\hline & Control & $23-49$ & 32.83 & 6.46 & \\
\hline \multirow{2}{*}{ Number of deliveries } & Experiment & $0-4$ & 1.31 & 1.22 & \multirow{2}{*}{0.88} \\
\hline & Control & $0-4$ & 1.28 & 1.18 & \\
\hline \multirow{2}{*}{ Work experience } & Experiment & $1-19$ & 8.71 & 4.86 & \multirow{2}{*}{0.77} \\
\hline & Control & $1-20$ & 8.98 & 5.11 & \\
\hline \multirow{2}{*}{ Performing physical activities } & Experiment & $0-7$ & 2.21 & 2.49 & \multirow{2}{*}{0.09} \\
\hline & Control & $0-7$ & 1.53 & 1.98 & \\
\hline
\end{tabular}

${ }^{*}$ Independent $t$-test.

these studies showed that lifestyle and its subdomains are closely associated with the self-efficacy of individuals. Also, after educational intervention, recognizing preventive behaviors, promoting health, and realizing that the ways to prevent the disease are cheap and simple, students found themselves able to perform preventive behaviors, and this increased their self-efficacy [37].

According to the results, the score of responsibility and self-fulfillment of individuals in the intervention group has increased significantly, while in the control group, there were no significant changes. In this regard, the study of Chenary et al. showed that the components of responsibility and self-actualization are associated with self-efficacy and change in one direction [38]. Ordun and Akün also showed that the flourishing of abilities and their application are directly associated with self-efficacy beliefs [39]. Another study done by Shcherbakova found that self-actualization was under the influence of a number of factors, one of the most important having positive beliefs about people's ability expressed in terms of self-efficacy [40]. The study of Charandabi et al. states that responsibility is associated with selfefficacy and emphasizes that responsibility is one of the characteristics of self-efficacious individuals [41]. A grounded theory study on female cancer survivors' experience of a psychological intervention for quality of life conducted by Durosini et al. showed that not only physical health but also self-actualization is one of the most important motivational reasons for healthy behaviors such as exercise [42].

The results of the present study also show a direct relationship between the component of interpersonal relationships and self-efficacy, as well as the effect of self-efficacy training on the component of interpersonal relationships. In their study, Saadat et al. stated that self-efficacy was associated with interpersonal relationships [43]. In a study, Siyez and Savi also pointed out the relationship between selfefficacy on the one hand and intimacy and empathy on the other hand, which emphasizes the existence of interpersonal 
TABLE 3: Mean and standard deviations of health-promoting lifestyle structures and self-efficacy in teachers under study.

\begin{tabular}{|c|c|c|c|c|}
\hline Variable & Group & Before intervention $($ mean $\pm \mathrm{SD})$ & After intervention $($ mean $\pm S D)$ & $P$ value \\
\hline \multirow{3}{*}{ Spiritual growth and self-actualization } & Intervention & $25.90 \pm 2.64$ & $30.30 \pm 5.97$ & $P<0.001$ \\
\hline & Control & $25.10 \pm 2.53$ & $25.38 \pm 2.54$ & $P=0.63$ \\
\hline & $P$ value & $P=0.89$ & $P=0.001$ & \\
\hline \multirow{3}{*}{ Health responsibility } & Intervention & $36.86 \pm 7.12$ & $41.38 \pm 6.91$ & $P<0.001$ \\
\hline & Control & $36.03 \pm 4.53$ & $36.43 \pm 5.94$ & $P=0.56$ \\
\hline & $P$ value & $P=0.44$ & $P=0.001$ & \\
\hline \multirow{3}{*}{ Interpersonal relationships } & Intervention & $21.05 \pm 2.16$ & $24.11 \pm 3.83$ & $P<0.001$ \\
\hline & Control & $20.96 \pm 2.23$ & $20.78 \pm 2.64$ & $P=0.35$ \\
\hline & $P$ value & $P=0.83$ & $P=0.001$ & \\
\hline \multirow{3}{*}{ Stress management } & Intervention & $15.71 \pm 2.10$ & $17.95 \pm 2.71$ & $P<0.001$ \\
\hline & Control & $15.76 \pm 2.13$ & $15.76 \pm 2.33$ & $P=0.74$ \\
\hline & $P$ value & $P=0.92$ & $P=0.001$ & \\
\hline \multirow{3}{*}{ Exercise and physical activity } & Intervention & $18.93 \pm 2.86$ & $21.11 \pm 3.90$ & $P<0.001$ \\
\hline & Control & $18.60 \pm 2.89$ & $18.53 \pm 2.46$ & $P=0.32$ \\
\hline & $P$ value & $P=0.95$ & $P=0.001$ & \\
\hline \multirow{3}{*}{ Nutrition } & Intervention & $19.06 \pm 2.49$ & $20.81 \pm 3.56$ & $P=0.004$ \\
\hline & Control & $19.10 \pm 2.54$ & $19.06 \pm 2.49$ & $P=0.44$ \\
\hline & $P$ value & $P=0.91$ & $P=0.002$ & \\
\hline \multirow{3}{*}{ Overall lifestyle score } & Intervention & $137.53 \pm 9.41$ & $155.68 \pm 24.58$ & $P<0.001$ \\
\hline & Control & $136.53 \pm 8.15$ & $136.96 \pm 8.79$ & $P=0.51$ \\
\hline & $P$ value & $P=0.53$ & $P=0.001$ & \\
\hline \multirow{3}{*}{ Self-efficacy } & Intervention & $53.86 \pm 6.51$ & $62.53 \pm 8.67$ & $P<0.001$ \\
\hline & Control & $53.75 \pm 6.63$ & $53.86 \pm 6.51$ & $P=0.12$ \\
\hline & $P$ value & $P=0.92$ & $P=0.001$ & \\
\hline
\end{tabular}

TABle 4: Pearson correlation coefficient between subscales of lifestyle and self-efficacy in teachers.

\begin{tabular}{lccccccccc}
\hline Variable & $\begin{array}{c}\text { Spiritual growth and } \\
\text { self-actualization }\end{array}$ & $\begin{array}{c}\text { Health } \\
\text { responsibility }\end{array}$ & $\begin{array}{c}\text { Interpersonal } \\
\text { relationships }\end{array}$ & $\begin{array}{c}\text { Stress } \\
\text { management }\end{array}$ & $\begin{array}{c}\text { Physical } \\
\text { activity }\end{array}$ & $\begin{array}{c}\text { Nutrition } \\
\text { lifestyle }\end{array}$ & $\begin{array}{c}\text { Overall } \\
\text { efficacy }\end{array}$ \\
\hline $\begin{array}{l}\text { Spiritual growth and } \\
\text { self-actualization }\end{array}$ & 1 & 0.870 & 0.913 & 0.797 & 0.591 & 0.798 & 0.927 & 0.567 \\
$\begin{array}{l}\text { Health responsibility } \\
\text { Interpersonal }\end{array}$ & 0.870 & 1 & 0.919 & 0.856 & 0.534 & 0.809 & 0.933 & 0.941 \\
relationships & 0.913 & $0 / 919$ & 1 & 0.881 & 0.677 & 0.780 & 0.954 & 0.918 \\
Stress management & 0.797 & 0.856 & 0.881 & 1 & 0.854 & 0.956 & 0.957 & 0.686 \\
Physical activity & 0.591 & 0.534 & 0.677 & 0.854 & 1 & 0.848 & 0.775 & 0.647 \\
Nutrition & 0.798 & 0.809 & 0.780 & 0.956 & 0.848 & 1 & 0.928 & 0.763 \\
Overall lifestyle & 0.927 & 0.933 & 0.954 & 0.957 & 0.775 & 0.928 & 1 & 0.853 \\
Self-efficacy & 0.567 & 0.941 & 0.918 & 0.686 & 0.647 & 0.763 & 0.853 & 1 \\
\hline
\end{tabular}

relationships [44]. However, these studies have not stated that self-efficacy takes precedence over interpersonal relationships, or vice versa, because they are cross-sectional.

The present study shows that increasing self-efficacy improves stress management and researchers' intervention was able to improve teachers' stress control. Our findings support Bandura's (1988) suggestion that self-efficacy has important implications for people's health and well-being [45]. Although previous research has shown that selfefficacy may affect how employees respond to stressful 
situations [46-48], our study shows that self-efficacy structures can influence how teachers respond to real-world issues and promote stress management. However, the study done by Jurado et al. reported different results and showed that people with higher self-efficacy were under more stress. Researchers have interpreted that people with high selfefficacy are more responsible and therefore more stressed [49]. The results of the present study can be interpreted in such a way that people with high self-efficacy are better able to overcome problems and thus better control their stress [22]. The results of the study by Alipour et al., which supports the results of the present study, indicate that in order to achieve better results and positive effects on stress, anxiety, and depression in pregnant women, self-efficacy techniques can be used in the implementation of the training program [50].

Table 4 also shows that the changes observed in the intervention group in the component of physical activity and self-efficacy are in one direction. A study conducted by Andenæs et al. shows that physical activity and self-efficacy are associated. According to the results of these studies, we can say that physical activity can have a positive effect on a person's self-efficacy due to increasing the level of health [51]. We can also say that self-efficacy creates an important motivating force for people to perform regular physical activity. A study of Ostovarfar et al. found that self-efficacy is effective in altering behaviors associated with physical activity. People who have strong self-efficacy beliefs are more capable of controlling physical and situational problems [52]. The results of studies show a two-way correlation between self-efficacy and physical activity. Therefore, studies show that the advantage of physical activity is not limited to its physical effects, but these activities affect all aspects of health $[52,53]$.

Nutrition and self-efficacy were also directly associated with one another in this study. The study of Hall et al. is consistent with the present study and states that healthy nutrition leads to an improvement in a person's lifestyle and has a positive effect on a person's self-efficacy [54]. Schultz DP and Schultz SE state that proper nutrition is in the realm of health-related behaviors that are governed by self-efficacy beliefs [55]. Sharma et al. have conducted a study on nutritional self-efficacy aimed at assessing people's self-efficacy in consuming healthy foods. This study reported a close relationship between self-efficacy and nutrition [56]. Of course, given that teachers are among the most educated groups in society, they are aware of the importance of exercise and healthy nutrition, and as a result, the training sessions showed better results.

In general, we can say that increasing self-efficacy among teachers also promotes their lifestyle. Because there is a twoway relationship between the variables in this study, we can conclude that improving the health-promoting lifestyle components in teachers has improved their self-efficacy beliefs and behaviors.

Finally, we suggest that, due to the sensitive role of teachers as an effective human force in the development and evolution of society and their students' role modeling, the authorities should formulate policies, regulate educa- tional interventions, and design strategies for promoting self-efficacy beliefs and promoting a healthy lifestyle for all teachers. We suggest that other methods and theories of behavior change be used in future studies to promote a healthy lifestyle. In this study, we have done educational intervention during two months; our suggestion is that future studies be conducted to investigate the continuity of behavior with longer follow-ups over several periods. This study also did not mention the effect of training in each session. This study was semiexperimental with limited sample size, so it is recommended that clinical trial studies be designed with a larger number of samples. Accordingly, we recommend that these cases be covered in future studies.

\section{Data Availability}

The statistical data used to support the findings of this study are included within the article.

\section{Ethical Approval}

Collection of the data was done after obtaining the necessary confirmation from the relevant authority and obtaining the code of ethics (IR.SUMS.REC.1398.296).

\section{Conflicts of Interest}

The authors have no conflict of interest in the publication of this article.

\section{Acknowledgments}

This project was financially supported by Shiraz University of Medical Sciences. It was performed by Fariba Abbasi as her Master's thesis in the field of health education, by registration number 18643 . We express our gratitude to the vicechancellor Shiraz University of Medical Sciences and all the people who provided the opportunity to do this research.

\section{References}

[1] A. Bonner, Local Authorities and the Social Determinants of Health, Bristol University Press, 2020.

[2] R. Uddin, E.-Y. Lee, S. R. Khan, M. S. Tremblay, and A. Khan, "Clustering of lifestyle risk factors for non-communicable diseases in 304,779 adolescents from 89 countries: a global perspective," Preventive Medicine, vol. 131, article 105955, 2020.

[3] S. S. Mazloomy Mahmoodabad, H. Tehrani, M. Gholian-Aval, H. Gholami, and M. Nematy, "The effect of social class on the amount of salt intake in patients with hypertension," Blood pressure., vol. 25, no. 6, pp. 360-363, 2016.

[4] M. Hoseini, T. Ashktorab, and M. Taghdisi, "Health-promoting lifestyles in nursing students," Health Promot Manag., vol. 2, pp. 66-79, 2013.

[5] World Health A, Prevention and control of noncommunicable diseases: outcomes of the high-level meeting of the general assembly on the prevention and control of non-communicable diseases and the first global ministerial conference on healthy lifestyles and noncommunicable disease control: report by the secretariat, World Health Organization, Geneva, 2012. 
[6] G. Caprara, "Mediterranean-type dietary pattern and physical activity: the winning combination to counteract the rising burden of non-communicable diseases (ncds)," Nutrients, vol. 13, no. 2, p. 429, 2021.

[7] Q. Gong, P. Zhang, J. Wang et al., "Morbidity and mortality after lifestyle intervention for people with impaired glucose tolerance: 30-year results of the da qing diabetes prevention outcome study," The Lancet Diabetes \& Endocrinology., vol. 7, no. 6, pp. 452-461, 2019.

[8] N. Khaltaev and S. Axelrod, "Chronic respiratory diseases global mortality trends, treatment guidelines, life style modifications, and air pollution: preliminary analysis," Journal of Thoracic Disease, vol. 11, no. 6, pp. 2643-2655, 2019.

[9] A. N. G. Sanchez, J. F. Sallis, K. J. Calfas, C. Rock, and K. Patrick, "Patterns and correlates of multiple risk behaviors in overweight women," Preventive Medicine, vol. 46, no. 3, pp. 196-202, 2008.

[10] A. Tamakoshi, K. Tamakoshi, Y. Lin, K. Yagyu, and S. Kikuchi, "Healthy lifestyle and preventable death: findings from the Japan collaborative cohort (jacc) study," Preventive Medicine, vol. 48, no. 5, pp. 486-492, 2009.

[11] M. D. Filipe, W. C. Meijers, A. Rogier van der Velde, and R. A. de Boer, "Galectin-3 and heart failure: prognosis, prediction \& clinical utility," Clinica chimica acta; international journal of clinical chemistry., vol. 443, pp. 48-56, 2015.

[12] A. Ahmadi, H. Soori, M. Mobasheri, K. Etemad, and A. Khaledifar, "Heart failure, the outcomes, predictive and related factors in Iran," Journal of Mazandaran University of Medical Sciences., vol. 24, no. 118, pp. 180-188, 2014.

[13] I. M. Rosenstock, V. J. Strecher, and M. H. Becker, "Social learning theory and the health belief model," Health Education Quarterly, vol. 15, no. 2, pp. 175-183, 1988.

[14] S. J. Hannan, "Yes, i can!: fostering self-efficacy in science at school," HSRC Review, vol. 19, no. 2, pp. 8-10, 2021.

[15] K. R. Glanz and B. Viswanath, Health Behavior Theory, Research, and Practice, JOSSEY-BASS, WILEY, 5 edition, 2015.

[16] L. M. Buchanan, M. El-Banna, A. White, S. Moses, C. Siedlik, and M. Wood, "An exploratory study of multicomponent treatment intervention for tobacco dependency," Journal of nursing scholarship: an official publication of Sigma Theta Tau International Honor Society of Nursing., vol. 36, no. 4, pp. 324-330, 2004.

[17] L. Ghahremani, M. Alipoor, S. Amoee, and S. Keshavarzi, "Health promoting behaviors and self-efficacy of physical activity during pregnancy: an interventional study," International Journal of Women's Health and Reproduction Sciences., vol. 5, no. 3, pp. 181-185, 2017.

[18] S. Babaei and S. Boroumand, "Relationship between lifestyle and cardiac self efficacy among people with heart failure," Cardiovascular Nursing Journal, vol. 5, no. 4, pp. 36-44, 2017.

[19] M. Solhi, S. S. Kazemi, and J. Yazdani, "The effect of educational intervention based on self-efficacy theory on general health status of women in Chaloos, Iran," Health and Development Journal, vol. 3, no. 2, pp. 150-162, 2014.

[20] A. Bandura, "Cultivate self-efficacy for personal and organizational effectiveness," in The blackwell handbook of principles of organizational behaviour, pp. 125-141, Wiley Online Library, 2017.

[21] T. Razi, M. Shamsi, M. Khorsandi, N. Roozbahani, and M. Ranjbaran, "Education and self-efficacy of mothers regard- ing alerting signs in children less than five years in Arak, Iran,” Scientific Journal of Hamedan Nursing and Midwifery Faculty, vol. 24, no. 1, pp. 1-8, 2016.

[22] A. Schwerdtfeger, L. Konermann, and K. Schönhofen, "Selfefficacy as a health-protective resource in teachers? A biopsychological approach," Health psychology: official journal of the Division of Health Psychology, American Psychological Association., vol. 27, no. 3, pp. 358-368, 2008.

[23] A. L. Zeldin, S. L. Britner, and F. Pajares, "A comparative study of the self-efficacy beliefs of successful men and women in mathematics, science, and technology careers," Journal of Research in Science Teaching: The Official Journal of the National Association for Research in Science Teaching., vol. 45, no. 9, pp. 1036-1058, 2008.

[24] M. K. Esquivel, C. R. Nigg, M. K. Fialkowski, K. L. Braun, F. Li, and R. Novotny, "Influence of teachers' personal health behaviors on operationalizing obesity prevention policy in _head start_preschools: a project of the _Children's Healthy Living Program_(CHL)," Journal of nutrition education and behavior., vol. 48, no. 5, 2016.

[25] H. Ali and J. Al-Asadi, "Prevalence and lifestyle determinants of hypertension among secondary school female teachers in Basrah," The medical journal of Basrah university, vol. 27, no. 2, pp. 90-94, 2009.

[26] A. Pirzadeh, G. Sharifirad, and A. Kamran, "Healthy lifestyle in teachers," Journal of Education Health Promotion, vol. 1, no. 1, pp. 46-47, 2012.

[27] A. Charkazi, G. M. Koochaki, H. Shahnazi, Z. Ekrami, and E. Bahador, "Lifestyle of teachers working in Gorgan city in 2009," Journal of Health System Research., vol. 6, no. 3, pp. 522-532, 2010.

[28] M. Solhi, F. E. Fard Azar, J. Abolghasemi, M. Maheri, S. F. Irandoost, and S. Khalili, "The effect of educational intervention on health-promoting lifestyle: intervention mapping approach," Journal of Education Health Promotion, vol. 9, no. 1, p. 196, 2020.

[29] S. Mackey, S. S. H. Teo, V. Dramusic, H. K. Lee, and M. Boughton, "Knowledge, attitudes, and practices associated with menopause: a multi-ethnic, qualitative study in Singapore," Health care for women international., vol. 35, no. 5, pp. 512-528, 2014.

[30] Health UDo, Services H, Theory at a Glance: A Guide for Health Promotion Practice, Lulu. com, 2018.

[31] S. Ashford, J. Edmunds, and D. P. French, "What is the best way to change self-efficacy to promote lifestyle and recreational physical activity? A systematic review with meta-analysis," British journal of health psychology., vol. 15, no. 2, pp. 265-288, 2010.

[32] F. Heidari, S. M. Khan Kermanshahi, and Z. Vanaki, "The effect of a supportive health promotion program on the lifestyle of premenopause teachers," Feyz Journal of Kashan University of Medical Sciences., vol. 17, no. 1, 2013.

[33] Z. A. Mohamadi, "Validity and reliability of the Persian version of health promoting lifestyle questionnaire," Journal of Mazandaran university of medical sciences., vol. 20, no. 1, pp. 103-113, 2012.

[34] B. Barati, The simple and multiple relationships between selfeffectiveness, self-discovery and self- esteem with academic performance of students in the third years of the new system in Ahvaz msc thesis, Shahid Chamran University of Ahvaz, Ahvaz. Iran, 1997. 
[35] M. Mirghafourvand, "Health-promoting lifestyle and its predictors among Iranian adolescent girls, 2013," International journal of adolescent medicine and health, vol. 26, no. 4, pp. 495-502, 2014.

[36] M. Amiri, R. Chaman, and A. Khosravi, "The relationship between health-promoting lifestyle and its related factors with self-efficacy and well-being of students," Osong public health and research perspectives., vol. 10, no. 4, pp. 221-227, 2019.

[37] A. Khani-jeihooni, M. Manouchehri, M. Bahmandoost, and Z. Khiyali, "Effect of educational intervention based on the health belief model on preventive behaviors against influenza a (h1n1) among students," Journal of Education and Community Health, vol. 7, no. 2, pp. 97-103, 2020.

[38] R. Chenary, A. Noroozi, S. S. Tavafian, and M. S. Firoozabadi, "Effective factors on health-promoting lifestyle among Iranian chemical veterans in 2014 based on health promotion model: a path analysis," Iranian Red Crescent Medical Journal, vol. 18, no. 8, p. e33467, 2016.

[39] G. Ordun and F. A. Akün, "Self actualization, self efficacy and emotional intelligence of undergraduate students," Journal of Advanced Management Science, vol. 5, no. 3, pp. 170-175, 2017.

[40] A. M. Shcherbakova, "Self-actualization of individuals with intellectual disability: role of the environment," Social welfare: Interdiscipnilary approach., vol. 1, no. 2, pp. 86-92, 2012.

[41] S. Mohammad-Alizadeh-Charandabi, M. Mirghafourvand, N. Tavananezhad, and M. Karkhaneh, "Health promoting lifestyles and self-efficacy in adolescent boys," Journal of Mazandaran University of Medical Sciences, vol. 24, no. 109, pp. 152-162, 2014.

[42] I. Durosini, L. Savioni, S. Triberti, P. Guiddi, and G. Pravettoni, "The motivation journey: a grounded theory study on female cancer survivors' experience of a psychological intervention for quality of life," International Journal of Environmental Research and Public Health., vol. 18, no. 3, p. 950, 2021.

[43] S. Saadat, F. Asghari, and R. Jazayeri, "The relationship between academic self-efficacy with perceived stress, coping strategies and perceived social support among students of University of Guilan," Iranian Journal of Medical Education, vol. 15, pp. 67-78, 2015.

[44] D. M. Siyez and F. Savi, "Empathy and self-efficacy, and resiliency: an exploratory study of counseling students in Turkey," Procedia-Social and Behavioral Sciences., vol. 5, pp. 459-463, 2010.

[45] A. Bandura, "Organisational applications of social cognitive theory," Australian Journal of management., vol. 13, no. 2, pp. 275-302, 1988.

[46] S. A. Panatik, M. P. O'Driscoll, and M. H. Anderson, "Job demands and work-related psychological responses among Malaysian technical workers: the moderating effects of selfefficacy," Work \& Stress., vol. 25, no. 4, pp. 355-370, 2011.

[47] J. Lloyd, F. W. Bond, and P. E. Flaxman, "Work-related selfefficacy as a moderator of the impact of a worksite stress management training intervention: intrinsic work motivation as a higher order condition of effect," Journal of occupational health psychology., vol. 22, no. 1, pp. 115-127, 2017.

[48] C.-q. Lu, O.-1. Siu, and C. L. Cooper, "Managers' occupational stress in China: the role of self-efficacy," Personality and Individual Differences., vol. 38, no. 3, pp. 569-578, 2005.
[49] M. M. Molero Jurado, M. D. C. Pérez-Fuentes, and N. F. Oropesa Ruiz, "Self-efficacy and emotional intelligence as predictors of perceived stress in nursing professionals," Medicina, vol. 55, no. 6, p. 237, 2019.

[50] M. Alipour, L. Ghahremani, S. Amooee, and S. Keshavarzi, "The effectiveness of relaxation techniques on depression, anxiety and stress in pregnant women: based on self-efficacy theory," Scientific Journal of Kurdistan University of Medical Sciences., vol. 22, no. 3, pp. 20-30, 2017.

[51] R. Andenæs, S. B. Bentsen, K. Hvinden, M. S. Fagermoen, and A. Lerdal, "The relationships of self-efficacy, physical activity, and paid work to health-related quality of life among patients with chronic obstructive pulmonary disease (copd)," Journal of Multidisciplinary Healthcare., vol. 7, p. 239, 2014.

[52] J. Ostovarfar, M. H. Kaveh, L. Ghahremani, S. Radmanesh, M. Fararooei, and A. Maghsoudi, "Does physical activity could moderate perceived wellness of health providers?," Shiraz E-Medical Journal., vol. In Press, no. In Press, 2017.

[53] J. S. Brach, E. M. Simonsick, S. Kritchevsky, K. Yaffe, A. B. Newman, and for the Health, Aging and Body Composition Study Research Group, "The association between physical function and lifestyle activity and exercise in the health, aging and body composition study," Journal of the American Geriatrics Society., vol. 52, no. 4, pp. 502-509, 2004.

[54] E. Hall, W. Chai, and J. A. Albrecht, "Relationships between nutrition-related knowledge, self-efficacy, and behavior for fifth grade students attending title i and non-title i schools," Appetite, vol. 96, pp. 245-253, 2016.

[55] D. P. Schultz and S. E. Schultz, Theories of personality: Cengage Learning, 2016.

[56] S. Sharma, L. Roberts, and S. Fleming, "Nutrition self-efficacy assessment: development of a questionnaire and evaluation of reliability in African-American and Latino children," Journal of Human Nutrition and Dietetics., vol. 27, pp. 160-166, 2014. 